\title{
Applying Geographic Information Systems to Support Strategic Environmental Assessment: Opportunities and Limitations in the Context of Irish Land-use Plans
}

\author{
Ainhoa Gonzalez \\ Technological University Dublin \\ Alan Gilmer \\ Technological University of Dublin, alan.gilmer@tudublin.ie \\ Ronan Foley \\ National University of Ireland, Maynooth
}

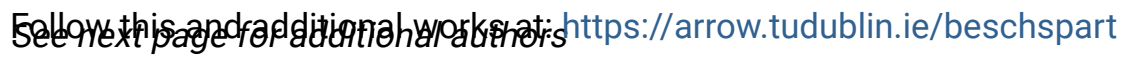

Part of the Environmental Health and Protection Commons, Environmental Indicators and Impact Assessment Commons, Environmental Monitoring Commons, Land Use Law Commons, Natural Resources and Conservation Commons, Natural Resources Law Commons, Natural Resources Management and Policy Commons, Risk Analysis Commons, and the Sustainability Commons

\section{Recommended Citation}

Gonzalez, A., Gilmer, A.,Foley, R., Sweeney, J. \& John Fry. (2010). Applying Geographic Information Systems to Support Strategic Environmental Assessment: Opportunities and Limitations in the Context of Irish Land-use Plans. Environmental Impact Assessment Review, Volume 31, Issue 3, April 2011, Pages 368-381. doi:10.1016/j.eiar.2010.12.001

This Article is brought to you for free and open access by the School of Transport Engineering, Environment and Planning at ARROW@TU Dublin. It has been accepted for inclusion in Articles by an authorized administrator of ARROW@TU Dublin. For more information, please contact arrow.admin@tudublin.ie, aisling.coyne@tudublin.ie,gerard.connolly@tudublin.ie.

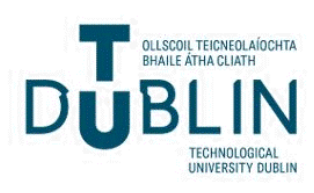


Authors

Ainhoa Gonzalez, Alan Gilmer, Ronan Foley, John Sweeney, and John Fry

This article is available at ARROW@TU Dublin: https://arrow.tudublin.ie/beschspart/7 


\title{
Applying geographic information systems to support strategic environmental assessment: Opportunities and limitations in the context of Irish land-use plans
}

\author{
Ainhoa González ${ }^{\mathrm{a}, *}$, Alan Gilmer ${ }^{\mathrm{a}, 1}$, Ronan Foley ${ }^{\mathrm{b}, 2}$, John Sweeney ${ }^{\mathrm{c}, 3}$, John Fry ${ }^{\mathrm{d}, 4}$ \\ a Department of Environment \& Planning, Dublin Institute of Technology, Zhivago Building, Bolton Street, Dublin 1, Ireland \\ ${ }^{b}$ National Centre for Geo-computation, National University of Ireland, Maynooth, Co. Kildare, Ireland \\ c Department of Geography, National University of Ireland, Maynooth, Co. Kildare, Ireland \\ d School of Biology and Environmental Science, UCD Dublin, Belfield, Dublin 4, Ireland
}

\section{A R T I C L E I N F O}

\section{Article history:}

Received 30 April 2010

Received in revised form 1 December 2010

Accepted 2 December 2010

Available online 31 December 2010

\section{Keywords:}

SEA

GIS

Land use plans

Republic of Ireland

\begin{abstract}
A B S T R A C T
The strengthening of spatial database infrastructures, further promoted by the INSPIRE Directive adopted in 2007, has led to an increased use of spatial data in planning and decision-making. Given that land-use plans are intrinsically spatial, such evidence and approaches can significantly benefit plan-making. A spatial framework could especially support the specific Strategic Environmental Assessment (SEA) aspects of the plan-making process. Spatial tools such as Geographic Information Systems (GIS) are particularly well-placed to support the environmental integration sought in SEA by providing evidence through the spatial assessment of multiple environmental datasets. Moreover, GIS bring the opportunity to augment conventional assessment techniques (e.g. matrix-based assessments) by acting as visual mediators of spatial knowledge and by providing an effective tool for the spatial and temporal analysis of environmental impacts.

This paper presents a GIS-based approach to SEA (GISEA), and analyses the above premise by evaluating the barriers, limitations, opportunities and benefits of its implementation. The GISEA approach has been applied to seven development plans of differing scales in the Republic of Ireland. The results of the case studies revealed that current issues in SEA (e.g. restricted time-frames and institutional arrangements) condition the implementation of a GIS-based approach. Moreover, GIS expertise, data accessibility and quality remain limiting factors to an effective GIS application in SEA. However, the results also confirmed that GIS have the potential to increase the objectivity and accuracy of the assessment, enhance both the understanding of environmental and planning considerations and the delivery of information, and, therefore, help to improve the effectiveness of SEA practice.
\end{abstract}

(c) 2010 Elsevier Inc. All rights reserved.

\section{Introduction: the potential of GIS in SEA}

Geographic Information Systems (GIS) are increasingly used to support decision-making in spatial planning. Given that development plans commonly link land use to location, spatial evidence and approaches can significantly benefit plan-making. Such a spatial framework could also support the specific Strategic Environmental Assessment (SEA) requirements of the plan-making process. Directive 2001/42/EC (CEC, 2001), commonly known as the SEA Directive, sets the requirements for the environmental assessment of plans and pro-

\footnotetext{
* Corresponding author. 298 Crumlin Road, Dublin 12, Ireland. Tel.: + 353876624879. E-mail addresses: ainhoag@yahoo.com, agonzal@tcd.ie (A. González),

alan.gilmer@dit.ie (A. Gilmer), ronan.foley@nuim.ie (R. Foley), john.sweeney@nuim.ie

(J. Sweeney), john.fry@ucd.ie (J. Fry).

${ }_{1}$ Tel.: + 35314023806 .

2 Tel.: + 3537086024 .

3 Tel.: +3537083684 .

${ }^{4}$ Tel.: + 3537167730 .
}

grammes (PP) that are likely to have significant environmental effects. SEA can be defined as a structured and participative procedure containing a set of tools to assist in the integration of environmental considerations and promote informed decision-making at PP level (González, 2010). The procedural requirements of the SEA Directive are commonly fulfilled through a series of actions undertaken during the plan-making process (namely: screening and scoping, description of PP alternatives, environmental baseline description, environmental assessment, mitigation measures, public consultation, and monitoring). The SEA process runs in parallel with plan-making, and culminates in the preparation of an Environmental Report (ER) to inform decisionmaking.

The methods and techniques applied in SEA vary (e.g. expert judgements, matrices, mapping and modelling). Matrix-based assessment techniques have probably been most widely used in SEA practice to date (Fischer, 2007; Therivel, 2004). Although matrices allow easy identification of conflicts and trade-off between PP and environmental objectives, they have a degree of subjectivity (Therivel, 2004), and often fail to address the spatio-temporal dimensions common to environmental and planning issues (Skehan and 
González, 2006; Vanderhaegen and Muro, 2005). GIS can overcome some of these restrictions by identifying the spatial and/or temporal variability amongst impacts (Patil et al., 2002), and have the potential to augment conventional techniques by providing spatial evidence to both the assessment and the plan-making processes (González et al., 2008a; González, 2010).

The use of spatial data and GIS in environmental assessment is promoted by Directive 2007/2/EC (CEC, 2007), for the creation of an INfrastructure for SPatial InfoRmation in Europe (INSPIRE). The INSPIRE initiative has also promoted the introduction of GIS into other environmental legislation, including the Water Framework Directive (CEC, 2000) and the Noise Directive (CEC, 2002), both of which require submission of certain geographic information in map form. It is anticipated that such an infrastructure will itself promote further use of spatial data by making relevant and quality geographic information available for the formulation, evaluation and monitoring of PPs (CEC, 2005). Although the SEA Directive does not formally require the use or generation of spatial datasets, it is considered that their application can provide several benefits when compared to traditional methods (González, 2010; Vanderhaegen and Muro, 2005).

Given the wide spatial and temporal scope needed for the SEA of PPs, the capabilities of GIS can confer significant advantages in the prediction and evaluation of spatially distributed and/or cumulative impacts. GIS facilitate the preparation of maps and, thereby, present a SEA support tool to illustrate and analyse data (Therivel, 2004), particularly in land use planning (Fischer, 2007). Presenting baseline data in graphic form improves the delivery of information, enhancing the understanding of the distribution, patterns and linkages between relevant environmental factors (DEHLG, 2004a; ODPM, 2005; Vanderhaegen and Muro, 2005). Therefore, GIS have the potential to facilitate a more robust spatial analysis as they enable integrating various datasets and visualising the juxtaposition or cumulative nature of different impacts (Harrison and Haklay, 2002). In addition, they enable the reuse of "old" datasets; combining them with current information incorporates a time-scale which facilitates the prediction of the cumulative effects of plans and projects over a number of years (Vanderhaegen and Muro, 2005). It can be argued that these advantages have the potential to lead to more transparent decision-making for spatial planning since decisions can be demonstrably based on spatially-specific and objective evidence (Skehan and González, 2006). Nevertheless, a number of constraints affecting the effectiveness of GIS have been reported, including data availability, accessibility, and costs, and data quality in terms of scale, completeness and currency (e.g. Rybaczuk and MacMahon, 1995; Vanderhaegen and Muro, 2005; van Loenen and Onsrud, 2004).

The exploration of empirical applications of GIS in SEA is limited, with most published literature focusing on one of the various SEA stages (e.g. Geneletti, 2008; Haklay et al., 1998). Similarly, the use of GIS within environmental assessment is underdeveloped in the Republic of Ireland ('Ireland' from hereon), their use being largely limited to mapping operations. Such limited experience probably constrains effective decision-making, given the documented advantages of applying GIS in environmental assessment and the opportunities for its incorporation. This paper focuses on assessing the capability of spatial data and GIS for enhancing SEA and examines the factors that enable/impede their effective application.

\section{Methodology}

The research methodology covered two core areas. Firstly, developing a GIS-based approach for SEA (GISEA) and, secondly, testing it in case study settings to ascertain the opportunities for and limitations to its application. Field observations were complemented with interviews of representatives from local authorities who had a central role in the preparation of the case studies. These were supplemented with a critical review of SEAs, which focused on their spatial comprehensiveness.

\subsection{Development of the GISEA approach}

The novelty of GISEA lays in the adaptation of existing GIS techniques to support SEA processes. GISEA was structured on a series of actions to be undertaken within the various SEA stages, incorporating spatial data and GIS tools where they could contribute to the process (Fig. 1). Therefore, GIS techniques were applied and customised to fit the requirements of each SEA stage. The approach relied on the ArcGIS family of products, particularly ArcView desktop and ArcIMS web server, as these provided the versatility needed.

\subsubsection{Basic spatial datasets for SEA in Ireland}

The availability and use of spatial data within Irish local authorities have significantly increased in the last decade. The majority of these datasets have been created at national (e.g. Natural Heritage Areas as part of the Natura, 2000 network), regional (e.g. River Basin District water risk assessments as part of the Water Framework Directive) and county level (e.g. Record of Protected Structures as part of the Irish Planning and Development Act 2000). The number of locally specific GIS-based studies (e.g. habitat surveys) is limited. Although a comprehensive array of both privately and publicly generated spatial data is available, no central spatial data repository exists in Ireland. Not all spatial datasets are in the public domain, and there is a lack of serious knowledge of datasets created by private businesses.

Annex I of the SEA Directive requires specific consideration of biodiversity, flora and fauna, population and human health, soil, water, air and climatic factors, material assets, cultural heritage and landscape. Relevant planning considerations may also be incorporated in the assessment with regard to existing and proposed infrastructure (e.g. transport corridors and waste water treatment plants), population changes (i.e. census data) and planning applications (e.g. location of new housing, industrial expansion zones, etc.) to address any socioeconomic needs and development pressure areas. Annexes I to III of the INSPIRE Directive (CEC, 2007) also list thematic layers relevant to SEA, such as protected sites or land cover. These considerations were used to develop a specific (albeit basic) thematic list of datasets, essential for a workable use of spatial information in SEA of land use

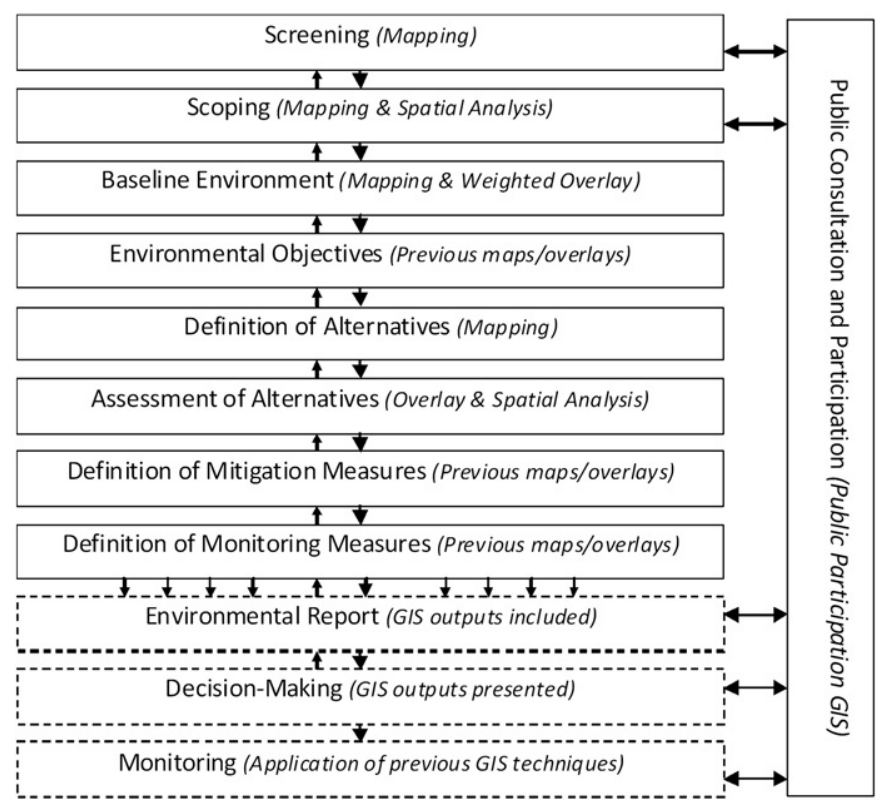

Fig. 1. SEA stages and GIS techniques applied in each of those stages. [Note that some SEA stages (e.g. definition of mitigation and monitoring measures) were assisted by maps and overlays prepared in the relevant previous stages.] 
plans (Table 1). Therefore, the inclusion of datasets in this checklist was based on the requirements of both the SEA and INSPIRE Directives and their availability. Prompt incorporation of these standardised and readily available datasets facilitated the assessment of key considerations at critical planning and decision stages. Although the type and number of layers necessary for each SEA may vary according to the scale and hierarchy of the plan, its information needs and the sector to which the SEA applies, resource and time restrictions often limit baseline data collection (Partidário, 2007; Wright, 2007).

\subsubsection{Determining the need for SEA and key environmental considerations}

GIS was not amenable to screening applications where the plan was automatically subject to SEA under statutory requirements (i.e. the study area population threshold of 10,000 persons set by the Irish Regulations, above which SEA is mandatory - DEHLG, 2004b), as they lack the ability to automate this type of process. However, the Regulations also require case-by-case screening where the population falls below 10,000 in order to determine whether the implementation of a plan would still be likely to have significant environmental effects. In such cases, mapping environmental sensitivities assisted in determining any need for SEA. Similarly, spatial analysis of environmental factors potentially affected by the plan was carried out during scoping. A request was submitted to each local authority to gather all relevant datasets concerning the status of environmental resources in the area (Table 1). These were overlaid and any spatial overlaps visually

\section{Table 1}

Principal spatial datasets available for SEA of land use plans in Ireland.

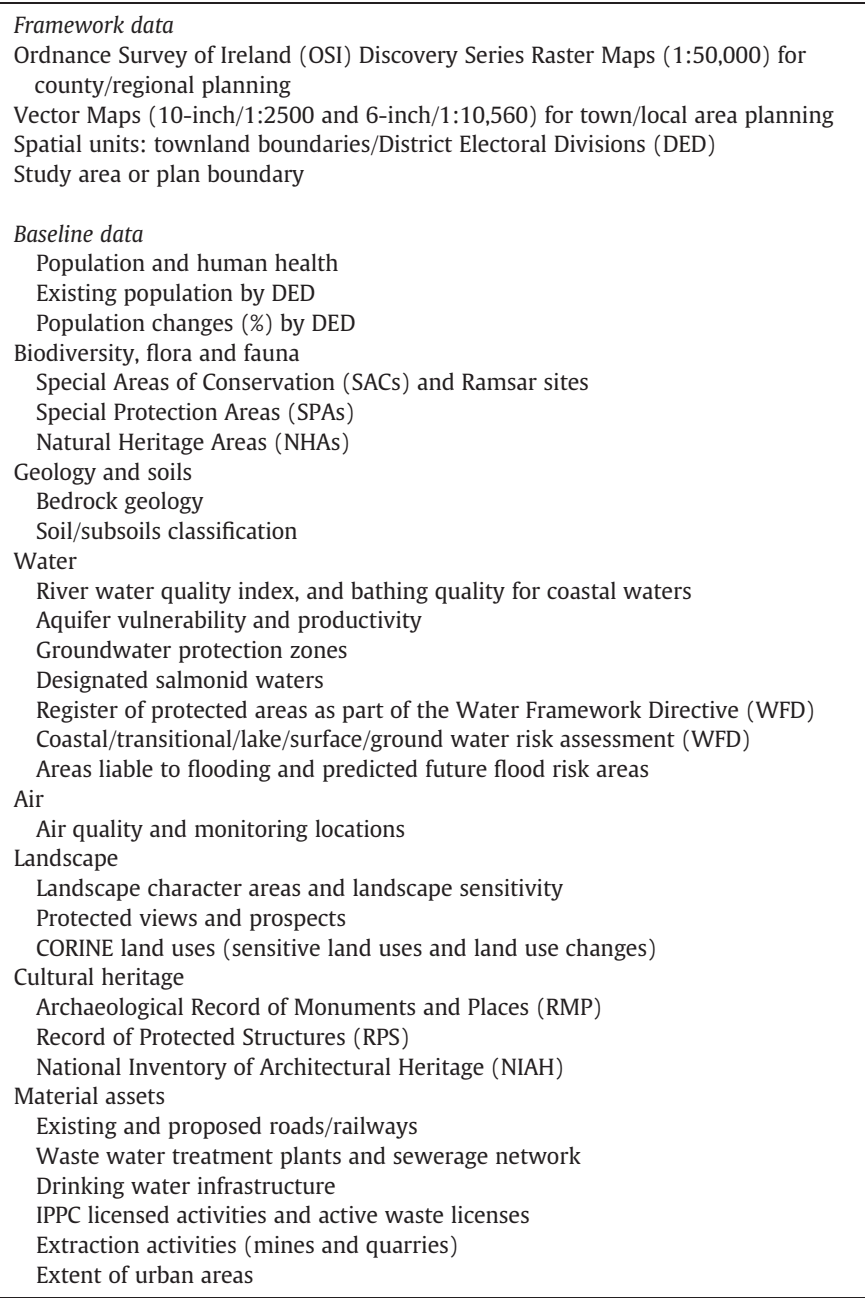

identified, drawing attention to key environmental sensitivity areas that needed further consideration. Such sensitivities were further evaluated when determining the environmental baseline, and used to facilitate and enhance the formulation of environmental objectives the methodological measures against which the effects of a plan can be tested.

\subsubsection{Determining the vulnerability to impact of the baseline environment}

Previously prepared environmental sensitivity maps were complemented with weighted overlay operations to further assess degrees of potential vulnerability to impact within the plan area. Weighted overlay is a GIS technique used to combine diverse datasets (e.g. co-occurring environmental sensitivity layers), and their relative importance (i.e. weights), into a unified analysis.

The principles of the impact assessment approach developed by van Straaten (1999) were adopted as the basis of GISEA. However, that approach was modified to prevent normalisation of results, as the averaging of effects allows for trade-offs but can neglect significant negative and cumulative effects. In this context, the premise of aggregation (Antunes et al., 2001) was implemented in the form of a weighted linear combination algorithm (Box 1), whereby the vulnerability of each area directly relates to the number of environmental criteria that overlap at one location. The results provided a vulnerability score, which merged cumulative sensitivity to impact of environmental receptors with the social importance of those receptors, providing an indication of the environmental vulnerability to impact of the different areas.

To facilitate weighted overlay operations and allow for the integration of weight values, vector data were converted to raster

\section{Box 1}

Weighted linear combination algorithm applied in GISEA.

$$
\mathrm{Vn}=\sum \mathrm{Wj} \mathrm{Vj}
$$

where:

Vn: resultant vulnerability score for the area, which relates to the total number $(\mathrm{n})$ of criteria that overlap.

Wj: significance value for each criterion ( $\mathrm{j}$ ) according to expert opinion. To standardise categorisations it was established that highly sensitive environmental factors - as established in current legislation, regulations and development plans (e.g. surface waters designated as being at risk [1a] under the Water Framework Directive or landscapes classified as highly sensitive in the County Development Plan) equated to 10 . Sensitive factors (e.g. surface waters designated as being potentially at risk [1b] or landscapes classified as sensitive) equated to 5 . A value of 0 was given to cells that had no-occurrence of environmental sensitivities.

$\mathrm{Vj}$ : public weighting of subjective nature, from stakeholders and the general public, on the importance of each criterion $(\mathrm{j})$. The weighting values $(\mathrm{Vj})$ were used as a 'strengthening' factor. Those aspects selected as more important by the public were given a weight of 1.5 that increased their significance. It was considered that the rest of the environmental criteria still had scientific significance and were, therefore, given a weight of 1.0. Although these values can be considered arbitrary, they were adopted to emphasise environmental parameters according to social values, while recognising that expert opinion is primary in SEA. 
format. To preserve sufficient detail for the assessment at county level the original vector data was rasterized to a cell size of $20 \mathrm{~m} \times 20 \mathrm{~m}$. Approximations to this cell size are commonly used in environmental mapping and assessments (e.g. Antunes et al., 2001; Geneletti, 2008; Legg and Taylor, 2006; Palmer, 2006; Vogt et al., 2007). This cell size can be adjusted to provide a higher level of detail for larger scale, or geographically smaller area, assessments such as Local Area Plans. Raster cells were subsequently reclassified according to their significance value $(\mathrm{Wj})$, and multiplied by the weighting values $(\mathrm{Vj})$. Ultimately, all concurring environmental criteria were added based on their absolute spatial location. These operations were intended to provide a total vulnerability value for each cell representing the sum of all the environmental sensitivities occurring at one location and their cumulative significance according to both expert and public opinions. The results yielded a thematic map reflecting these computed values, which were categorised to reflect the degree of vulnerability to impact of each area (Fig. 2).

\subsubsection{Establishing significance and weight values for environmental criteria} European and Irish legislation, together with the relevant development plans were consulted to establish the significance of environmental criteria $(\mathrm{Wj})$ as per Box 1 . In addition, the prescribed environmental authorities (Environmental Protection Agency - EPA, Department of Environment, Heritage and Local Government - DEHLG; Department of Communications, Marine and Natural Resources - DCMNR) were formally consulted during scoping. Their expert judgments with regard to the relative sensitivity of environmental resources were also taken into consideration when establishing significance values.

As the importance of issues can vary with the evaluator, a participatory approach (engaging stakeholders and the general public,

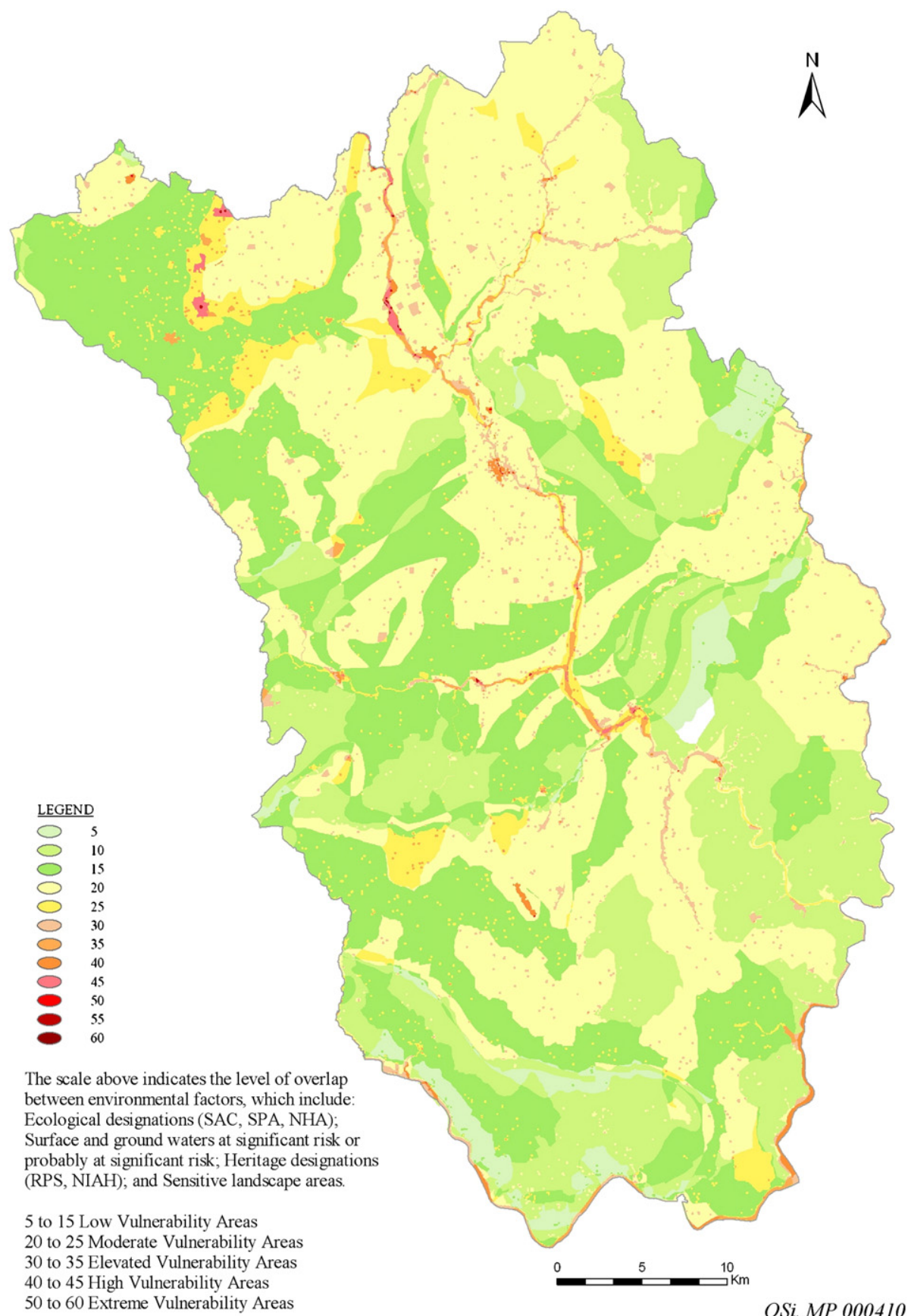

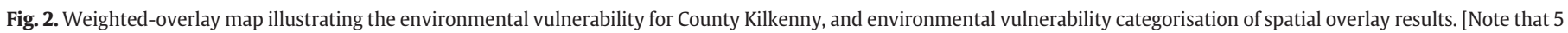
represents the lower vulnerability score (see Box 1 ) and that 0 score, representing no environmental sensitivities, does not apply to this case study.] 
in addition to the environmental authorities) was considered necessary to combine values derived from expert opinions with social perceptions on the importance of environmental criteria obtained during public consultations (González et al., 2008a). Although this approach could be contested, as weighting values can be arbitrary and open to debate (Towers, 1997), the inclusion of even a crude participation weighting was considered both symbolically and politically important. Nevertheless, inclusion of public weightings proved impossible due to the limited amount of meaningful public feedback.

The public weighting $(\mathrm{Vj})$ was to be obtained through a public participation GIS tool (GISEA website). This was designed to enable the spatial visualisation of information, assist in the weighting of environmental criteria, and gather perceptions on proposed alternatives (González et al., 2008a). Users were given a multiple-choice option in relation to environmental aspects (based on Table 1) and asked to select the environmental criteria of importance $(\mathrm{Vj})$. The GISEA website subsequently displayed a map showing the selected criteria for users to interact with the information. Personal perceptions, observations and comments could be submitted via semistructured questionnaires, linking opinions to a location on the map. The website also contained a rated voting system, allowing users to rank the proposed planning alternatives. These qualitative and quantitative data were gathered on a database for future incorporation into the assessment.

\subsubsection{Assessing planning alternatives}

The spatial representation of considered alternatives (compiled at workshops with the plan-making team and subsequently transferred into GIS) facilitated their subsequent integration with baseline information, thus assisting in their evaluation. Environmental assessment approaches commonly contrast proposed development against environmental vulnerabilities to establish the degree and likelihood of impact (e.g. Antunes et al., 2001; Geneletti, 2008; van Straaten, 1999). The GISEA assessment approach was based on the same principle; quantifying development pressure areas (e.g. urban, industrial and commercial) against relative vulnerability levels within the study area. This was achieved by clipping the areas under development pressure off the vulnerability map and computing the surface area (in $\mathrm{m}^{2}$ ) of lands vulnerable to impact. It was considered that this would contribute to the identification of the most favourable alternative (e.g. located in low vulnerability areas) and to the understanding of the relative significance of potential impacts (e.g. extent of development pressure areas on highly vulnerable lands), as well as facilitating the identification of spatially-specific remedial action (e.g. re-zoning of lands or mitigating by avoidance).

\subsubsection{Mitigation and monitoring}

Contrasting potentially conflicting land uses (e.g. residential development) against environmental vulnerability maps assisted in determining spatially-specific and quantifiable mitigation measures that could also be mapped (e.g. "no residential development within $50 \mathrm{~m}$ of shoreline" equates to a $50 \mathrm{~m}$ 'no-go' buffer zone along the coastline). This should facilitate monitoring and development control by updating indicator values associated to the spatial datasets and graphically representing any changes at a given location. However, the practical evaluation of the potential for GIS use during monitoring was not possible as none of the case study plans were fully adopted before the completion of this research. Notwithstanding this limitation, it was considered that updating relevant environmental information in spatial format (e.g. recording the location of monitored water quality values), illustrating the location and sprawl of development taking place within the lifespan of the plan and repeating the GIS procedures established in the various SEA stages had the potential to facilitate rapid and evidence-based monitoring of spatially-specific indicators. This monitoring approach would potentially allow early detection of land use conflicts and thereby assist in development control and impact mitigation decisions (Haklay et al., 1998).

\subsection{Testing the GISEA approach}

The GISEA methodology was tested in real-life land use plans within the context of the Irish planning system. The perceived benefits and barriers derived from its application were subsequently gathered from practitioners involved in the case studies.

\subsubsection{Case studies}

The case studies comprised of the County Development Plans (CDPs) of Mayo, Kilkenny and Offaly; the Kilkenny City and Environs Development Plan (CEDP); and the Local Area Plans (LAPs) of Blessington, Spiddal, and Wicklow Environs and Rathnew. These seven plans represented varying geographical and planning contexts, allowing comparison of results among land use plans within Ireland and facilitating an evaluation of outcomes within the same hierarchies of the planning system.

The environmental sensitivities differed across the case studies. County Mayo for example, is largely covered by peatland and encompasses important SAC and SPA habitats spread throughout the county, while ecological designations cluster along the main river corridors in County Kilkenny where water quality is one of the main issues. Similarly, development pressures differed (e.g. intensive forestry and growth in the wind energy sector in County Mayo, versus urban expansion exceeding infrastructural capacity in certain areas of County Kilkenny).

The planning hierarchy defined the geographical extent and the level of detail of both the plan and the assessment. County Development Plans entailed larger geographic areas and, thereby, broader and more complex environmental issues, and generally included non-spatial policies and actions. CEDPs and LAPs considered smaller geographic areas and addressed more specific aspects, planning in detail the location of different land uses within the study area where environmental issues became more spatially-specific. These considerations affected the applicability and effectiveness of the methodology.

\subsubsection{Practitioner interviews}

Opinions on the applicability of GIS to SEA in Ireland were sought from 8 planners, 6 technicians and 2 consultants involved in the case studies, as well as from 3 external representatives (EPA, DEHLG and Heritage Service). Separate questionnaires, addressing specific SEA- and GIS-related issues in a distinct manner, were prepared for each target group to semi-structure the interviews. The questionnaire for planners tackled SEA-related aspects, such as the potential of GIS to assist the various SEA stages (e.g. can spatial data assist in the definition of alternatives?), as well as the overall outcome of the process (e.g. can GIS improve the quality of ERs?). It also sought information about the adopted assessment methods (e.g. expert-judgments, matrix- or GISbased), and evaluated which SEA stages were perceived as benefiting most from spatial data. Technicians were asked about GIS data quality, accessibility and disclosure issues (e.g. what data constraints, if any, existed?). Perceptions in relation to potential benefits and constraints of applying GIS to SEA were sought from all consulted individuals (e.g. which were the main benefits/constraints when using spatial data and applying GIS?). Recommendations on how to improve current SEA practice and enhance GIS use in environmental assessment were also gathered from the relevant authorities.

Questionnaires for interviewing the consultants and representatives of environmental authorities focused on information relating to the expertise/experience of those individuals (e.g. why the statutory SEAs published to date made little use of GIS/how can INSPIRE contribute to the use of spatial data in environmental assessment?). They also tackled more general aspects to gain further insight into the perceived validity of incorporating a GISEA approach. 
Table 2

Framework and procedural criteria applied to examine the applicability of the GISEA methodology.

\begin{tabular}{|c|c|}
\hline Framework aspects (non-technical) & Procedural aspects (technical) \\
\hline $\begin{array}{l}\text { 1. Spatial nature of elements (i.e. } \\
\text { hindering the inclusion of relevant } \\
\text { non-spatial aspects into a GIS-based } \\
\text { assessment). }\end{array}$ & $\begin{array}{l}\text { 9. Replicability of the GISEA approach } \\
\text { and flexibility to adapt to SEA types } \\
\text { and planning contexts. }\end{array}$ \\
\hline $\begin{array}{l}\text { 2. Available resources and GIS skills of } \\
\text { personnel operating the system. }\end{array}$ & 10. Data availability and format. \\
\hline 3. Data sharing and access. & $\begin{array}{l}\text { 11. Inclusion of metadata or quality } \\
\text { statements in datasets. }\end{array}$ \\
\hline $\begin{array}{l}\text { 4. Systematic and focused approach to } \\
\text { SEA (e.g. application of methodical GIS } \\
\text { techniques and relevant datasets). }\end{array}$ & 12. Currency and completeness of data. \\
\hline $\begin{array}{l}\text { 5. Time-effective application of GIS } \\
\text { techniques and timely provision of GIS } \\
\text { outputs. }\end{array}$ & 13. Scale and spatial accuracy of data. \\
\hline $\begin{array}{l}\text { 6. Generation and release of concise } \\
\text { information (e.g. precise, clear and } \\
\text { spatially-specific). }\end{array}$ & $\begin{array}{l}\text { 14. Inclusion of indicators in datasets } \\
\text { (i.e. embedded indicator values). }\end{array}$ \\
\hline $\begin{array}{l}\text { 7. Participative methods (e.g. public } \\
\text { access to GIS and environmental data, } \\
\text { and public input into the assessment). }\end{array}$ & $\begin{array}{l}\text { 15. Comprehensiveness of GIS outputs } \\
\text { (e.g. amount and enhanced scope of } \\
\text { information). }\end{array}$ \\
\hline $\begin{array}{l}\text { 8. Acceptance and integration of GIS } \\
\text { outputs into SEA and decision-making } \\
\text { (e.g. relating to institutional } \\
\text { arrangements and power structures). }\end{array}$ & $\begin{array}{l}\text { 16. Reliability and accountability of GIS } \\
\text { outputs (e.g. validity of techniques } \\
\text { applied and quality of information). }\end{array}$ \\
\hline
\end{tabular}

\subsubsection{Comparative review of published SEA environmental reports}

The 41 statutory SEAs for land use plans published in Ireland before 31 January 2008 were reviewed to determine the inclusion of all SEA Directive requirements, and their comprehensiveness and adequacy from the perspective of spatial coherence and understanding. In light of the intrinsic spatial nature of land use plans, the criteria for analysing the ERs was largely based on the level of inclusion/exclusion of maps and written geographic references to environmental and planning considerations in the relevant sections.

Where the descriptions made no reference to location or context, these were judged to be non-spatial, and were commonly broad and vague. Where the descriptions referred to specific locations and/or adjacent relevant features/landmarks, the information was considered to be more concise and precise. Therefore, the latter approach to documenting relevant aspects arguably provided better and more comprehensive information for decision-making. In addition, when descriptions were supported with figures, maps and/or tables, the reader was provided with additional relevant detail, potentially improving information delivery and understanding.

\subsection{Assessing the applicability of the GISEA methodology}

The possible positive or negative outcomes of the case studies, the review of SEAs and the answers obtained from practitioners' interviews were examined from two core perspectives based on the approach adopted by Fischer (2002), namely framework (i.e. context related non-technical aspects) and procedural (i.e. of technical nature). Therefore, the applicability of GISEA was evaluated as either framework opportunities (linked to the capacity to facilitate and have an effect on SEA decision-making) or limitations (e.g. institutional arrangements and power structures). Similarly, procedural benefits (derived from improvements in environmental/planning data) and barriers to its effective application (e.g. availability and quality of spatial datasets) were investigated. To facilitate the analysis, framework and procedural effectiveness criteria were established (Table 2). These combined the performance criteria for SEA effectiveness portrayed in the literature (Barker and Wood, 2001; Fischer, 2007; Fischer and Gazzola, 2006; Fischer and Seaton, 2002; IAIA, 2002; Runhaar and Driessen, 2007; Therivel and Minas, 2002) with factors for effective GIS use (Hanzl, 2007; João, 1998; Vanderhaegen and Muro, 2005).

\section{Case study results and practitioners' perceptions}

Although GIS played a central role in the provision, management, assessment and delivery of information in all seven case studies, the GISEA methodology was fully applied in only four. Judged on the basis of the previously established criteria (Table 2), field observations and practitioners' perceptions, the applicability of GISEA and its contribution to SEA differed amongst the case studies (Table 3). The degree of implementation to each SEA stage and, thereby, the success/failure

Table 3

The applicability of GISEA in the case studies measured by the previously established effectiveness criteria (Table 2).

\begin{tabular}{|c|c|c|c|c|c|c|c|}
\hline Effectiveness criteria & Mayo CDP & Kilkenny CDP & Offaly CDP & Kilkenny CEDP & Blessington LAP & Wicklow LAP & Spiddal LAP \\
\hline \multicolumn{8}{|l|}{ Framework (non-technical) } \\
\hline 1. Spatial nature of factors & $x$ & $x$ & $x$ & $x$ & $x$ & $x$ & $x$ \\
\hline 2. GIS expertise & $\swarrow$ & $\prec$ & $\swarrow$ & $\prec$ & $\prec$ & $\prec$ & $\prec$ \\
\hline 3. Data sharing and access & $\square$ & $\swarrow$ & $\swarrow$ & $\swarrow$ & $\swarrow$ & $\prec$ & $\swarrow$ \\
\hline 4. Systematic approach & $\swarrow$ & $\prec$ & $\swarrow$ & $\prec$ & $\prec$ & $\prec$ & $\prec$ \\
\hline 5. Timely provision of outputs & $\square$ & $\prec$ & $\square$ & $\prec$ & $\square$ & $\prec$ & $\square$ \\
\hline 6. Dissemination of information & $\swarrow$ & $\swarrow$ & $\swarrow$ & $\swarrow$ & 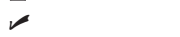 & $\prec$ & $\swarrow$ \\
\hline 7. Participative GIS & $\swarrow$ & 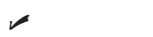 & $\swarrow$ & $\prec$ & $x$ & $x$ & $x$ \\
\hline 8. Integration of outputs & $\swarrow$ & 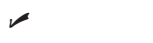 & $\prec$ & $\prec$ & $\prec$ & $\prec$ & $\prec$ \\
\hline \multicolumn{8}{|l|}{ Procedural (technical) } \\
\hline 9. Replicable/flexible method & $\prec$ & $\swarrow$ & $\swarrow$ & $\swarrow$ & $\prec$ & 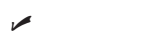 & $\swarrow$ \\
\hline 10. Data availability and format & $\square$ & $\prec$ & $\prec$ & $\prec$ & $\prec$ & $\prec$ & $\prec$ \\
\hline 11. Inclusion of metadata & $x$ & $x$ & $x$ & $x$ & $x$ & $x$ & $x$ \\
\hline 12. Data currency/completeness & $\square$ & $\square$ & $\square$ & $\square$ & $\square$ & $\square$ & $\square$ \\
\hline 13. Data scale/spatial accuracy & $\swarrow$ & $\prec$ & $\prec$ & $\swarrow$ & $x$ & $x$ & $x$ \\
\hline 14. Inclusion of indicators & $x$ & $x$ & $x$ & $x$ & $x$ & $x$ & $x$ \\
\hline 15. Comprehensiveness & $\swarrow$ & $\prec$ & $\prec$ & $\prec$ & $\prec$ & $\prec$ & $\prec$ \\
\hline 16. Accountability of outputs & $\square$ & $\square$ & $\square$ & $\square$ & $\square$ & $\square$ & $\square$ \\
\hline
\end{tabular}

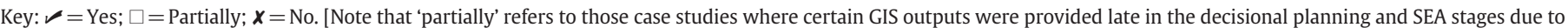

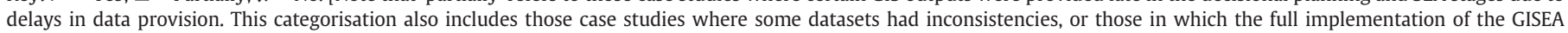
approach was not possible.] 
of GIS to support the SEA process, largely depended on recurring framework and procedural aspects, as discussed next.

\subsection{Framework considerations}

\subsubsection{The effect of planning structures and institutional attitudes}

Planning structures and institutional arrangements within the local authorities affected both planning and SEA processes (Fischer and Gazzola, 2006). In the case studies, the plan-making context and the attitudes of the planning-team towards SEA impinged upon the applicability of GISEA. All the case study SEAs were undertaken externally and, in all cases, the SEA and the planning processes ran in parallel rather than occurring in an integrated manner. Institutional arrangements restricted communication channels between the planning and SEA teams, and information was exchanged at decisional planning stages only - i.e. where the plan-making process required feedback from the SEA process (on, for example, which mitigation measures to include in the plan).

The GISEA approach was approved and adopted by the consultants and, consequently, the plan-making team accepted its incorporation. The 'spatial thinking' of the planners generally facilitated the inclusion of spatial data and GIS in all the case studies. Nevertheless, their level of GIS awareness, as well as their personal leverage in facilitating the adoption of a GIS-based approach, affected the implementation of GISEA. Local authorities with a well-established GIS unit swiftly provided the requested datasets that were internally available, and assisted in data improvement operations, enabling the application of GIS during scoping and baseline environment stages. The GIS-based approach to the definition of alternatives was adopted in all the cases studies, but not without certain reservations. Although all proposed alternatives were ultimately mapped (and in 4 case studies evaluated against vulnerability maps), the demarcation of specific land use areas was of particular concern at high-level planning due to the implications of zoning such large areas (particularly for Offaly CDP). These concerns could be linked to the general reluctance in the political process to publicly accept future explicit limitations on the scope for decision-making (Skehan, 2004). Public participation GIS (available in 4 of the case studies) was also affected by reticent attitudes towards data sharing and limited SEA time-frames.

Therivel and Minas (2002) note that the effectiveness of SEA can be measured in terms of environment-related changes to the plan. The planners involved in the case studies agreed that SEA workshops and consultation exercises raised the awareness of the plan-making team. However, the majority of interviewed planners $(7 / 8)$ perceived that the influence of the SEA in the final plan (e.g. how much had the SEA shaped the plan) remained unclear. The case studies illustrated this. Although all SEA stages were adequately undertaken and GIS was methodically applied, the process yielded a stand-alone ER and accompanying maps. Generally the SEA outputs were not directly included in the draft plan; only the draft Mayo CDP explicitly incorporated the mitigation measures recommended in the ER. Consequently, it can be argued that this reflects a form of marginalisation of the SEA process and its outcomes.

The interviewed practitioners perceived that current Irish planning arrangements also tend to marginalise SEA, since plan drafting procedures are prioritised, with inadequate time and resources provided to fulfil the requirements of the SEA Directive, and the environmental assessment process is perceived as a burden to planmaking. In Ireland the final planning decision belongs to elected members who, according to the interviewed consultants and planners, commonly neglect the SEA process and its outcomes, prioritising social, economic and political gain over environmental protection. Therefore, it can be argued that despite their capacity to facilitate the understanding of potential impacts and land use conflicts, current planning and decision-making cultures do not render GIS outcomes as efficient as they could. The extent to which
GIS have the potential to become an effective instrument to support SEA processes in Ireland is determined by the institutional framework within which it is applied.

\subsubsection{Timing of GIS as a support tool in SEA}

In the majority of the case studies (5/7), the SEA process started late (i.e. once the plan was drafted). In addition, late/delayed incorporation of relevant spatial information affected all the case studies to a greater or lesser extent. Although local authorities generally became proactively involved and promptly supplied all the available data requested, delays of 1-6 months in being able to source some data were encountered in certain cases (e.g. eskers for Offaly CDP or tree protection orders for Blessington LAP). In two case studies, these delays extended until a week before the ER submission date. Delays commonly related to the lack of readily available datasets within the local authority or accessibility constraints (e.g. formalising license agreements), but also resulted from necessary data conversion (e.g. from MapInfo to ArcView) and quality improvement tasks (e.g. rectifications of omissions and inaccuracies related to both feature and attribute data).

Time constraints were exacerbated by the time-frame restrictions in the lower planning tiers (e.g. shorter contractual period for undertaking SEA of LAPs), by changes in the SEA programme or, sometimes, by the prolongation of certain planning tasks - which subsequently reduced the time available to undertake the appropriate SEA steps and apply the relevant GIS techniques. Where the SEA time-frame was limited, other SEA tasks were prioritised (e.g. preparation of baseline maps and definition of alternatives). In such cases, weighted overlays were excluded (for Blessington and Spiddal LAPs) or limited to the use of transparency tools to visually identify the degree of overlap of cooccurring constraints (as in the case of Mayo CDP). This hindered the incorporation of the subsequent methodological steps envisaged, such as the spatially-specific assessment of Mayo CDP alternatives against the environmental vulnerability map. Time restrictions associated with the shorter time-frames allocated to the lower planning tiers also hindered the publication of the GISEA website in the LAP case studies.

The consultants involved in the case studies noted that data collation took too much time and effort, and that SEA would be potentially quicker if a central repository of environmental spatial data existed (such as the one created by the EPA). Nevertheless, they stated that once data were gathered, the GISEA approach significantly reduced the amount of time needed to identify and assess key issues, based on the environmental vulnerabilities and potential land use conflicts in the study area. This was corroborated by the EPA, who have developed a GIS-based tool to optimise personnel and resources, and reduced the time needed to undertake scoping and respond to consultations.

\subsubsection{Spatial literacy and GIS skills affecting IT-based public participation}

The GISEA website was adapted to each of the case studies to accommodate contextual parameters. Due to data licensing issues and the perceived sensitivity of the early disclosure of certain information, the Mayo CDP public consultation website excluded Ordnance Survey Ireland (OSI) base maps and proposed alternatives. Therefore, information displayed in the GIS interface was limited to relevant environmental layers. In the case of Kilkenny CDP and CEDP and Offaly CDP, OSI maps and proposed planning scenarios were included, providing more comprehensive information than in the Mayo CDP case study. In three of the four cases, the official local authority link flagged the GISEA website as a research study rather than an additional public consultation tool and, in all cases, the access link to the website was not immediately obvious - several intermediary web pages constraining its easy retrieval. A very limited number of hits were registered (an average of 5-8 in each of the case studies), and no comments were submitted to the GISEA website during the consultation period. Access to technology is argued to limit the scope for Internet-based participation (Kangas and Store, 2003; Kingston, 
1998). However, in all the cases where the GISEA website was made available, the local authority received on-line submissions, indicating that access was not the main constraint impeding GISEA use. Nevertheless, it is worth noting that a significantly larger amount of written submissions were received (e.g. 401 written submissions on the draft Offaly CDP and 3 on the associated SEA, versus 42 on-line submissions on the draft plan and none on the SEA).

The greater majority of respondents (11 of 13 planners, consultants and external representatives) considered that using spatial data can improve the transparency of the SEA process, promote debate and facilitate public consultation. However, this was not apparent in the case studies in light of the GISEA website outcomes. The nature of pull technologies in the Internet - where the request for data originates from the user performing a search (Käpylä et al., 1998) - can potentially limit the retrieval of information contained in a website. In the case studies, an abundance of existing intermediary web pages impeded easy retrieval of the GISEA website and, arguably, its usability. Additional factors likely to have affected its usability include a potential mistrust in technology or IT-based participation portrayed by the higher number of written submissions received.

A significant minority of the interviewed practitioners (7/19) considered lack of spatial and computer literacy as primary constraints to GIS use (in interactive Internet-based public participation), followed by a lack of specific GIS skills (for professional use within planning procedures). They observed that the lay public may have educational impediments for understanding maps; a barrier that would be exacerbated when using GIS-based interfaces. These observations correlate with spatial literacy and 'digital divide' issues (Brooks et al., 2005; Kingston, 1998; Oden and Lentz, 2001). Four respondents also noted that the public do not commonly engage in forward planning possibly due to the broader and more strategic policies envisaged, the lack of direct locally unwanted land use effects, and mistrust in decisionmaking systems. This observation supports Carver (2003), who noted that the willingness to become actively involved is lacking across populations.

\subsubsection{Spatial versus non-spatial considerations}

The current approach to strategic planning in Ireland, where objectives, policies and actions are often formulated in broad, imprecise and non-spatial terms - particularly at regional and county level (Skehan, 2004), affected the general applicability of GISEA. Such policies and actions, found to a greater or lesser extent in all the case studies, could not be integrated into the GIS-based assessments as they lacked spatial specification and, therefore, could not be linked to a geographic location.

All proposed alternatives were ultimately mapped, but divergences were observed among the case studies in the usefulness of GIS when defining these. High-level planning generally entails broader and more strategic alternatives, while in lower planning tiers the alternatives commonly render exact boundaries and specific land use zonings. Therefore, higher levels of uncertainty may be contained in the GIS layers illustrating high-tier land use zonings. This was reflected in the concerns raised by planners when determining land use zonings at this planning level which related, among other things, to developing broad and strategic policies and to assuming the boundaries to be definite rather than indicative. In contrast, City and Environs Development Plans and Local Areas Plans focus on smaller geographic areas and address more spatially-specific aspects, such as the detailed locations and boundaries of the different land uses within the borough limits. At this lower planning hierarchy the spatial definition of alternatives was facilitated by GIS. The feedback obtained during the interviews supported this observation.

Although large-scale plans are anticipated to become more spatially-specific (Skehan, 2004), the non-spatial formulation of policies and actions commonly found in current strategic planning documents constrains both their graphic representation and the spatial comprehension of their implications. Maps and graphics have a limited scope for assessing some of the broader and more strategic objectives in a DP (e.g. 'to improve service delivery through the Irish Language from public bodies' - Spiddal LAP). As a result, and notwithstanding that the generated maps contributed and complemented the assessment of alternatives, this SEA stage remained widely dependant on conventional assessment approaches (e.g. matrices). Non-spatial considerations also hindered the explicit and precise formulation of the associated mitigation and monitoring measures.

\subsection{Procedural considerations}

\subsubsection{Data accessibility and availability considerations}

Although the majority of data were provided by the local authorities involved in the case studies, data also originated from a number of other organisations (e.g. OSI, EPA, Geological Survey of Ireland, etc.). Sourcing the relevant datasets and resolving data copyright and associated license agreements, especially in relation to OSI mapping, generally hindered the timely incorporation of certain datasets into the assessment, particularly during scoping (4/7 case studies). Accessibility was also constrained by costs and copyright. Although local authorities commonly have an annual OSI licence agreement, several of the GIS technicians interviewed noted that the cost of such licenses is one key barrier to implementing GIS. Copyright and licensing issues for OSI data were of particular significance in the Mayo CDP, where the full incorporation of relevant layers in the GISEA website was constrained by the lack of approval for publication of these third party datasets. This affected the quantity and quality of information provided, subsequently affecting public consultation. In the remaining three case studies - where proactive attitudes towards data sharing facilitated the preparation and publication of the website, third party data were published with clear copyright/licence statements.

Although the lack of a central repository for spatial data in Ireland was a critical aspect affecting data retrieval, the frequently reticent attitudes towards spatial data sharing, particularly with regard to some sensitive information (e.g. granted planning applications), and accessibility (such as those resulting from license agreements) were a common cause of delays in data provision. In contrast, the more proactive approaches to data exchange of the Kilkenny and Offaly GIS technicians resulted in all available datasets being provided to the SEA team within a week of their request. Spatial variations in data accessibility practices across the country were apparent in the case studies.

Not all the relevant datasets were available at key decisional stages during the case studies, particularly during scoping and baseline environment, due to delays in data provision or to absolute lack of data. In such cases (a more prominent issue at the local level), assessment was undertaken using expert judgement and provided to planners as literal descriptions, statistics, etc. Where datasets were available, these were incorporated into GIS to prepare baseline and vulnerability maps, subsequently assess planning alternatives and, where applicable, publish them in the GISEA website.

\subsubsection{Data quality and scale issues}

The use of multiple spatial datasets in the GIS-based assessment, created to different standards by different organisations, rendered outcomes that could not be guaranteed for quality or certainty. All case studies contained some inconsistencies in certain datasets with regard to scale (e.g. the 25 ha resolution used in CORINE 2000 dataset versus the $100 \mathrm{~m}$ resolution used in the 2006 update), currency and incidence (e.g. the last update of the CORINE dataset was undertaken in 2006; current land uses are unknown but comparison with the first dataset prepared in 1996 provides historical evidence of land use 
changes), completeness (e.g. spatial gap detected in the surface water risk assessment for County Offaly) or positional accuracy (e.g. the soils layer for County Mayo did not match the county boundary, rendering a spatial gap with no soil classification).

Datasets were checked for consistency and any identified gaps on feature topology or attribute information correspondingly corrected and completed. However, the general lack of metadata in Irish datasets affected the prompt establishment of their relevance, validity and quality for the purpose of the study. In addition, the attribute information associated with the features rarely included indicators, which impeded rapid identification of the status of environmental resources, reducing their usability. These data quality considerations were preset constraints in the datasets used. The current availability of environmental and planning datasets resulted in data-driven assessments, limiting the extent to which spatial considerations could be analysed using GIS and to which accountability of results could be guaranteed.

The datasets available in Ireland (and in most European countries) are commonly collated and generated at small-scale (i.e. at county or regional level). This is a key consideration for GIS-based assessments. The SEA Directive requires a tiered SEA system, addressing solely those environmental aspects that are relevant to the decision-making level (Therivel, 2004). Therefore, the level of detail of the data applied at each decisional level in the planning hierarchy should reflect the contents and level of detail of the plan. In this context, the more specific the plan (e.g. LAP) the greater the level of detail (i.e. the larger the scale) is required in the datasets utilised during the assessment. The spatial resolution of Irish datasets is more appropriate for smallscale mapping and assessment; the level of spatial detail of the datasets being significantly reduced at large-scale or local level. Since the level of detail for the zoning of land uses is greater at large-scale planning levels, adopting the scale of available datasets compromised the accuracy of assessments in the Kilkenny CEDP and the Spiddal and Blessington LAP. In this regard, the research confirmed that the tiered approach to GIS-based environmental assessment is commonly constrained by the scale at which datasets are available.

\subsection{The perceived contribution of GIS to SEA}

Despite the observed framework limitations and procedural barriers, all the interviewed practitioners concurred that the incorporation of spatial data and GIS enabled the provision of clearer and spatially-specific information, which consequently enhanced under- standing, raised awareness on the environmental implications of a plan, and improved communication between planning and environmental decision-making. As a result, it was perceived that GIS had the potential to improve both SEA processes and ERs, facilitate planmaking and better inform decision-making (Fig. 3). All the involved practitioners considered that the maps produced in the case studies assisted in identifying and understanding land use conflicts and development opportunities. The graphic representation of environmental aspects promoted 'spatial thinking', as noted by one of the interviewed planners. GIS were also perceived by the consultants as having a vital role in the definition of alternatives, particularly at the LAP level. The overlay of environmental and planning considerations was considered by a majority (12/13 planners, consultants and external representatives) to be the most significant advantage, facilitating rapid and accurate identification of land use conflicts. A planner suggested that this approach promoted a more adequate consideration of potential land use conflicts when formulating policies and actions (which suggests a form of 'SEA by osmosis'). GIS were also perceived as potentially assisting in the definition of mitigation and monitoring measures, and facilitating monitoring processes with their ability to rapidly update and display additional data - although this could not be confirmed in this research. These perceived advantages compare with the reported benefits of GIS (Antunes et al., 2001; Harrison and Haklay, 2002; João, 1998; Vanderhaegen and Muro, 2005).

The consultants involved in the preparation of the SEAs perceived that the availability of maps during planning workshops and public consultation stages facilitated information delivery and understanding of issues. Moreover, they agreed with planners that the inclusion of maps articulated the ERs and facilitated the dissemination of information. All concurred that the methodology had the flexibility to be adapted to the planning context and the available data, and provided valuable results to both the drafting of the plan and the decision-making process. However, they also noted that data availability and quality issues could have serious implications on the reliability of GISEA results.

The above observations were validated by a comparative review of SEAs prepared between June 2004 and January 2008. The analysis revealed that a simple majority (68\%) of ERs included maps or geographic figures, generally used to depict the baseline environment. As a result, the associated ERs contained more spatially-specific, concise and comprehensive descriptions and assessments - despite the fact that, in the majority of cases (82\%), the assessment of

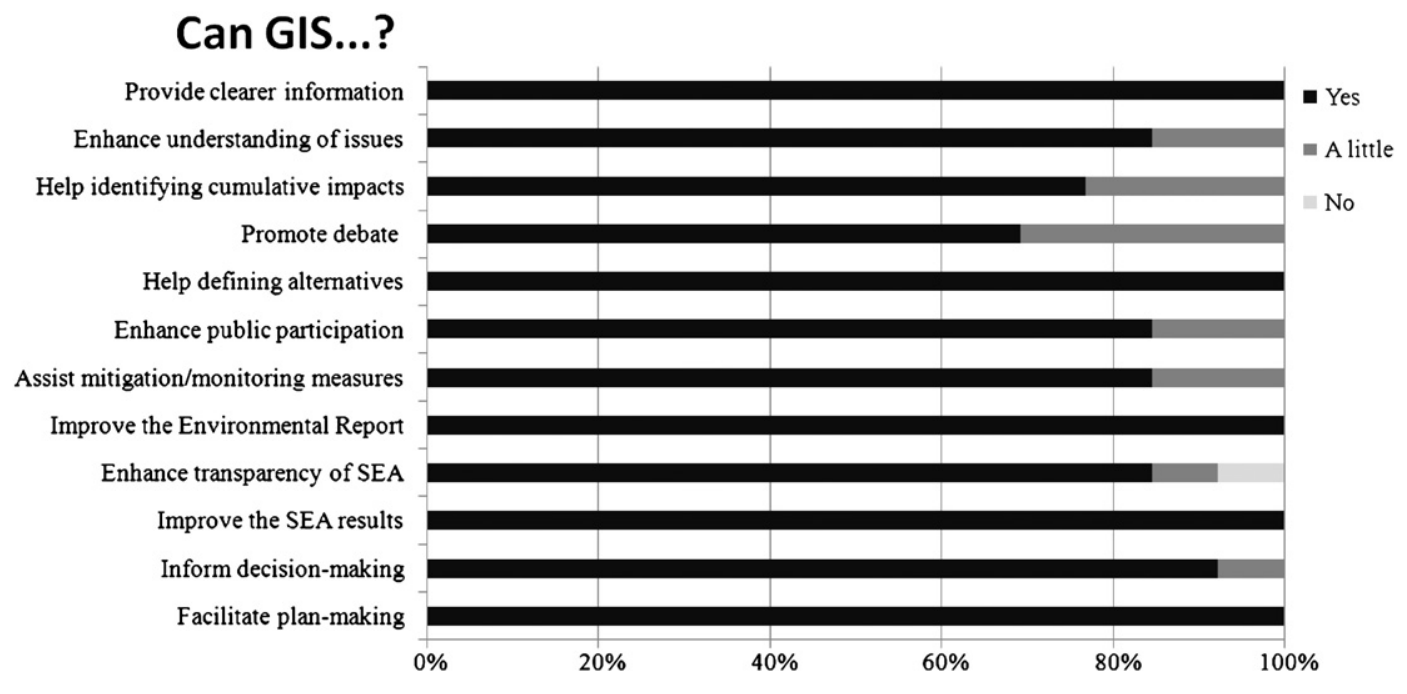

Fig. 3. Perceptions of 19 practitioners interviewed on the contribution of GIS to SEA. 
alternatives was commonly undertaken using a matrix approach. It was observed that where spatial data was not used, the relevant sections frequently included broad and vague descriptions that lacked both quantitative information and accurate assessments (e.g. 'slight to moderate increase in pollution in a number of lakes' - extract from West Meath CDP 2008-2014 SEA). Such broad statements diminished the quality and comprehensiveness of ERs. The review of the ERs also revealed that the inclusion of spatial data in the description of the baseline environment commonly rendered more precise and detailed assessment of alternatives, mitigation and monitoring measures. While it is probably unrealistic to assume that the more maps, tables and spatially-specific descriptions were included, the more complete and precise the ERs were, this was generally indicative of the analysis undertaken.

\section{Discussion: addressing framework and procedural considerations}

GIS are increasingly used in environmental assessment and widely incorporated in both EIA and SEA practice (Vanderhaegen and Muro, 2005). Nevertheless, they are under-exploited in Ireland, where GIS applications are largely limited to planning studies, but where there is significant scope for expansion through transfer to the associated SEA. SEA practice in Ireland has largely evolved from its integration into the existing land use planning system. It has emerged as an activity to be carried out rapidly and pragmatically, working against statutory deadlines, using incomplete information and attempting to engage non-specialists (officials, elected members and the general public) in using the findings to support decision-making (Skehan, 2004). Therefore, SEA techniques need to be more effectively adapted to the Irish context, and must convey clear and meaningful information in a rapid and effective way. It is increasingly obvious that the assessment of likely significant environmental effects is critically dependent upon the spatial representation and analysis of both environmental sensitivities and likely patterns of development (Skehan and González, 2006). The requirements of the INSPIRE Directive, and the capacity of GIS tools for spatial representation and assessing environmental and planning considerations, jointly identify a clear role of spatial data in certain SEA-related tasks. The intrinsic spatial nature of land use plans strengthens the ability of GIS to support SEA processes associated with spatial planning. In this context, Vanderhaegen and Muro (2005, pp 138) observed that: "GIS applications allow for better identification, more accurate description, better quantification, and improved evaluation of spatial and temporal variability of impacts, as well as for prediction of cumulative effects".

Fischer (2003) suggests that efficient SEA outcomes can be obtained by providing an adequate set of agreed rules for interaction and decision-making that may closely follow 'traditional' systematic EIA-based approaches. Dalal-Clayton and Sadler (2004) observed that the SEA Directive prescribes a procedure that draws heavily on the EIA Directive. However, SEA should aim at improving rather than assessing PPs, as well as effectively integrating environmental considerations into plan-making (Partidário, 2000). The GISEA approach described here relies on EIA-based SEA approaches (where emphasis is put on the provision, consideration and integration of environmental information throughout the stages of the plan-making process). Although it primarily focuses on assessing the environmental effects of implementing a PP, the provision of a systematic and participative methodology for each SEA stage, together with the visual representation of environmental issues and planning conflicts, emphasises aspects that can potentially improve plan-making.

Based on the case study findings, it could be argued that GIS improve the 'operational effectiveness' of SEA as they enhance the quality and quantity of environmental/planning information by incorporating the geographic dimension (Budic, 1994). This statement was supported by the interviewed practitioners and validated by the comparative assessment of SEAs, which revealed that the inclusion of spatial data articulated and enhanced the comprehensiveness of ERs. Notwithstanding that greater precision and more data do not necessarily mean better results, this inference was based on the premise that spatial data can facilitate more accurate assessment and that maps can improve information delivery (Antunes et al., 2001; Budic, 1994; Harrison and Haklay, 2002; João, 1998, 2007; Vanderhaegen and Muro, 2005). The review outcomes indicated that the content of the ERs prepared with the aid of GIS were more spatiallyspecific, concise and precise (as opposed to the broad descriptions, non-spatial references to environmental considerations and vague assessments observed in the ERs that did not avail of the visual and analytical benefits of GIS). However, the potential of spatial data and GIS to enhance SEA practice can only be effectively applied if appropriate framework and procedural conditions are in place, as the findings of this research suggest.

\subsection{Optimising framework conditions}

Institutional arrangements and decision-making cultures generally conditioned the extent to which GIS could improve the SEA process in the case studies. Existing institutional frameworks and attitudes impeded the adoption of certain steps in the methodological approach (e.g. public participation GIS) and challenged others (e.g. spatial definition of alternatives). Despite the spatial awareness of planners, or perhaps as a result of it, the definition of sharp zoning boundaries was frequently a reason for concern. The Irish planning system further limits the extent to which GIS can be effectively applied in SEA. The availability, quantity and quality of data in the case studies, particularly in the lower planning tiers, were affected by the decisional time-scales (i.e. 35 weeks for the preparation of LAPs and 99 weeks for CDPs and CEDPs). When applying a GIS-based approach to SEA, the time needed for data gathering and integration can affect the efficiency of such an approach (by failing to provide the required outputs for each decisional stage in a timely manner). If sufficient and appropriate data are not provided on time at the relevant 'decision windows' (Dalkmann et al., 2004), the analysis of data may well become redundant (Partidário, 2007). In the context of the case studies, the provision of key GIS-compatible datasets (Table 1) generally optimised the time and resources needed for the preparation of baseline maps. This was not the case when more specific datasets were required (e.g. tree protection orders or granted planning applications). Timely data collation and incorporation might not have been an issue had SEAs been undertaken in-house, since the majority of datasets might have been readily available. It is therefore argued that the creation of a central data repository and more relaxed attitudes towards data sharing would ensure a more effective and timely application of the GISEA approach. Nevertheless, the influence of SEA and, arguably, the impact of GIS in the final decision remain constrained by existing power structures and hierarchical responsibilities in the Irish planning system, where the final decision belongs to elected members, often rendering SEA ineffective.

This also reflects on public participation, as context and power structures largely restrict participative GIS approaches (Hanzl, 2007). Public interactions with GIS-based interfaces to retrieve information and submit comments are largely experimental and very few practical applications have been implemented in participatory planning (e.g. Horita, 2000; Jordan and Shrestha, 2000; Kingston et al., 2000; Simão et al., 2009; Weiner and Harris, 2003). Although, as the case studies have demonstrated, it is argued that participatory GIS cannot be effective on its own, there is strong international support for the use of GIS as a complementary tool in public participation processes (González et al., 2008b). However, the apparent risk to the interests of developers, assessors or decision-makers influencing the filtering and representation of spatial information (Towers, 1997; Harrison 
and Haklay 2002; Siebenhüner and Barth, 2004) needs to be carefully addressed. Information manipulation was apparent in the Mayo CDP website, where fear of disclosure affected the comprehensiveness of the information conveyed to the public and, as a result, the scope and validity of public consultation.

The empirical results of this research indicate that Goodchild's prediction (2006), of an increasingly GIS-enabled society as a result of Internet-based mapping tools, may still not be the case in Ireland. Online submissions are widely implemented in Irish local authorities, but the pre-requisites of spatial literacy and GIS knowledge are far from realised.

\subsection{Optimising procedural conditions}

Despite the framework limitations, the methodology was not fully effective in the case studies, mainly due to procedural constraints. The observed lack of consistent quality in datasets, gaps in spatial and attribute information and the non-spatial nature of certain aspects (and their consequent exclusion from assessment) affected the reliability of GISEA outputs. The SEA Directive states that assessment is to be based on existing data sources and that no additional data collection is required. Therefore, the lack of a full inventory of available datasets in Ireland and unavailable spatial information for certain environmental considerations may have led to excluding and, consequently, overlooking relevant aspects in the spatial assessment. These issues have been acknowledged as common in Europe. Lillethun (2002), supported by Vanderhaegen and Muro (2005), reported that data sharing, lack of connection among and between potential data users and data producers, gaps in the availability of datasets, lack of harmonisations in data quality and duplication of information collection, are key issues at the European level. Although no transboundary SEAs were undertaken as part of this research, it should be noted that these issues are potentially more significant in such cases, due to the discontinuity of information across national boundaries, and the common lack of data sharing mechanisms (Bartley, 2007).

The benefits of GISEA are enhanced when using standardised and readily accessible datasets. Therefore, effective GIS application is reliant on the existence of either a centralised body with the necessary resources for the set-up and maintenance of spatial data from different source organisations, or a distributed GIS network for bringing all available datasets into a single interface. It is anticipated that both the INSPIRE Directive and the Irish Spatial Data Infrastructure (ISDI) initiative (i.e. the agreed framework of metadata, technology, policies and standards that enable the discovery, use and distribution of spatial data) will contribute to the standardisation and improved accessibility of spatial datasets. Under these initiatives, spatial datasets from different sources could become widely available, and seamlessly used and combined in SEA processes. Until INSPIRE/ISDI are fully implemented, lack of a centralised spatial data repository and existing institutional resistance towards data sharing will continue to significantly affect data access and provision. In any case, the discretionary nature of some INSPIRE provisions are likely to limit its full potential. Article 17 of the INSPIRE Directive provides a margin of discretion to Member States, whereby public authorities supplying spatial datasets and services have the right to licence and/or require payment for them. If this Article applies, a number of datasets relevant to SEA may never be freely available. This is of particular relevance for OSI datasets. The DEHLG is currently considering formulating a Pan-Governmental Agreement for bulk-data-buying. This could facilitate data provision at reasonable or marginal costs, and subsequent marginal pricing would improve accessibility (Rhind, 2008).

Datasets must be kept up to date and contain comprehensive information (Rybaczuk and MacMahon, 1995), the geographic extent, spatial accuracy and level of detail of data must be appropriate and feature attribute information must be correct and complete for reliability of results (João, 1998). However, these data quality aspects are not always achievable, and data inconsistencies and uncertainties in SEA are not always avoidable. In effect, Rybaczuk and MacMahon (1995) reported a number of data quality and accessibility problems in Ireland (e.g. format incompatibility, currency, completeness and scale), many of which remain issues today and have been observed during the case studies. Format incompatibility issues have been resolved with the commercialisation of conversion software and tools (most GIS packages currently have a file conversion tool embedded). However, drawing files (such as AutoCAD) are still commonly employed in both engineering and planning sectors. These generate 'legacy data' (lacking attribute information and, in most cases, topology), which affects their integration and reduces their informational validity for spatial assessment purposes. The common lack of indicators in Irish datasets also represents a key aspect affecting their usability.

Spatial scale is a core factor affecting data quality and assessment accuracy (João, 2002). In the context of the Irish planning system, a County Plan is commonly represented at 1:50,000 scale, while 6-inch (i.e. 1:10,560) maps or 1:2500 vector datasets are used at local area level. However, the relevant environmental datasets are available at the scale at which they were collated, which in most cases reflects a county or regional context. The research indicates that GIS might be most useful in SEAs at lower planning tiers. Land use plans at that scale tend to be more spatially-specific, explicitly zoning lands and evaluating potential environmental issues in great detail. The reported benefits of GIS in EIA (Antunes et al., 2001; Harrison and Haklay, 2002; Vanderhaegen and Muro, 2005) would be equally applicable in these lower SEA tiers that resemble EIA frameworks. At this local level, the effects of space, place and proximity become relevant fostering greater public interest and participation and, arguably, greater uptake of public participation GIS (Carver, 2003).

Nevertheless, in Ireland (and in most European countries) environmental data are commonly generated at small-scale (i.e. county or regional levels). This small-scale approach to data gathering/creation impinges upon the level of detail provided at a large-scale or local level. As a result, and despite the potential for GISEA being intensified at local planning level, the scale of available datasets undermines their full capacity at this level, rendering results that may be imprecise or not accurate enough. This scale conundrum (i.e. 'scale of application' versus 'spatial scale and quality' of datasets) incorporates new considerations into the applicability of GISEA. In the current absence of locally-specific environmental datasets, GIS can be considered more useful in the higher planning hierarchies. Ironically, this data-driven approach to GIS application (i.e. conditioned by the datasets available) is limited by the general reluctance to explicit zone areas at such planning levels. Therefore, the potential of GIS can be optimised by improving the quality and spatial accuracy of datasets for application in all planning levels, and by enhancing spatial awareness among planners to promote 'spatial thinking' throughout the planning hierarchy.

Data quality, completeness and scale inconsistencies can be rectified by updating, correcting or improving the relevant information, but the additional time and effort required may hamper the timely incorporation of datasets into the assessment. In all cases, the general lack of metadata in Irish datasets impeded establishing their fitness for use (i.e. quality) and fitness for purpose (i.e. usability). Technical issues could be better dealt with by enforcing metadata requirements and creating an independent body to appraise data quality. The creation of data control mechanisms could also help in ensuring that data creators provide standardised and quality datasets.

As outputs largely rely on the quality of inputs, a GIS-based methodology may not provide fully reliable results. Data inconsistencies, errors and gaps are inevitable in any practical database (Onsrud, 1999) - as confirmed by the case studies, but their severity and implications vary from project to project. Data comprehensiveness and accuracy often rely on the purpose, gathering method or scale adopted for data collection - aspects that were pre-determined for the datasets 
used in the Irish case studies (Table 1). João (1998, p. 157) observes that the effective use of GIS is "closely tied with understanding the nature of spatial data and how data quality might affect the end results'. The lack of a clear understanding of data usability and scale, accuracy and quality limitations may lead to the inappropriate use of GIS in data applications, which could then lead to inconsistent or inaccurate results. In the context of SEA, the lack of quality control and resulting accuracy issues in final results will not only affect the end decisions, but also the credibility of agencies and organisations involved in the process.

Therivel (2004) observes that SEA is subject to great levels of uncertainty as a result of the ambiguity about future environmental, economic and social conditions. Partidário (2007) reinforces this observation, suggesting that data accuracy and quality aspects are overcome with some acceptance that SEA often needs to deal with higher levels of uncertainty. Due to such greater complexity and larger geographic context, it is generally accepted that environmental aspects in SEA cannot be described in great scientific and spatial detail (João, 2007; Therivel, 2004). Therefore, uncertainty can be addressed by accepting that GIS and spatial data provide indicative areas and results (which may or may not need additional and detailed assessment depending on the end purpose of the study), rather than acting as definitive planning tools. In all cases, residual uncertainty and gaps in data must be acknowledged in the relevant ER to determine or estimate the validity of the GIS outcomes and ensure transparent decisionmaking (Hunter, 1999). In the context of the case studies, the identified data errors were communicated to planners and data gaps and limitations reported in the relevant ERs.

The GISEA approach is based on contemporary GIS operations and can be adapted to specific data requisites, geographical extent and content analysis of different plan-making and SEA contexts. In other words, GISEA has the flexibility to be adapted to case-specific requirements (such as scale, shape and size of study area or environmental criteria considered). As noted by the practitioners involved, GISEA facilitated a systematic and comprehensive SEA process, providing all relevant datasets are available, by:

- rendering information in a spatially-specific and transparent manner;

- spatially and methodically assessing multiple environmental considerations and addressing their potential commonalities and interrelationship;

- facilitating the visual identification of potential land use conflicts, consequently improving the understanding and awareness of potential issues; and

- allowing for the integration of public participation results into the assessment.

The GISEA methodology enhanced the transparency and objectivity of assessments when compared to the commonly applied matrixbased methods (as it provided a systematic and replicable approach that applied the same set of techniques throughout the various SEA stages and used datasets that could be visualised and modified at any stage). The subsequent adoption and incorporation of approximations to the GISEA methodology in the SEA of several in-house CDPs prepared outside the scope of this research (e.g. Cork and South Dublin CDPs) underlined its applicability and corroborated the usefulness of the methodology.

\section{Conclusion}

This research has demonstrated that spatial data and GIS can play a significant role in supporting SEA by providing spatial evidence, integrating and assessing multiple issues and values in a more objective and precise manner, and conveying the assessment outputs in a concise and visual manner to improve the understanding, all of which arguably should have a positive effect on drafting the plan.
Nevertheless, the research has also revealed that effective GIS application is currently constrained by several contextual limitations and technical barriers. The current approach to strategic planning in Ireland restricts the general applicability of the methodology, since strict time-frames and prioritisation of planning tasks hinder timely data gathering, and objectives and policies are often formulated in broad and non-spatial terms. Moreover, once datasets are gathered, these may still contain inconsistencies that impinge upon their readiness. Belated incorporation of spatial datasets commonly leads to inadequate provision of information at decisional stages in the planning process. Reservations over copyright and data publication can also affect the timely publication of certain spatial datasets, and limit public participation GIS (although this is also affected by underdeveloped spatial awareness and IT knowledge).

Procedural barriers also hinder GISEA effectiveness. Issues of data availability, accessibility, compatibility and quality (including the common lack of indicator values), and more importantly lack of metadata, can affect all SEA stages. These aspects can have serious implications for the reliability of GISEA outputs. Acknowledging any data limitations in the ERs, and recognising the potential risk of providing unreliable GIS and, therefore, SEA outcomes can enhance transparency and help validate the credibility of results.

Achieving the full capacity of GIS to affect decision-making goes beyond resolvable issues of spatial dataset quality and the validity of GIS-based assessment outcomes. Overcoming procedural constraints through full access to current and accurate spatial datasets and their adequate management would not automatically make SEA better. Framework issues prevail in the form of institutional arrangements, affecting both the applicability of GIS and, in particular, the effectiveness of SEA. Investigation of decision-making cultures in Ireland would help better understand current limitations to proactive environmental integration.

Further research is required to devise measures to strengthen GIS approaches in the planning system, and to fully incorporate them into SEA (including the more complex stages of mitigation and monitoring). Additional research is also required to advance understanding on spatial data issues. In particular, undertaking a sensitivity analysis of existing Irish spatial datasets will help establish their quality and validity for SEA; in this regard, the effects that a national repository and data quality mechanism would have in the implementation and applicability of GIS also need to be explored in detail. Notwithstanding the extensive research undertaken in public participation GIS, it is considered that future research should focus on devising mechanisms to effectively factor in public perceptions into SEA. Research and practice need to be expanded to ascertain the full potential of GISEA approaches, but the practical applications embedded in this research have already had a direct impact on the level of GIS use in Irish SEA.

\section{References}

Antunes P, Santos R, Jordao L. The application of geographical information systems to determine environmental impact significance. Environmental Impact Assessment Review 2001;21(6):511-35.

Barker A, Wood C. Environmental assessment in the European Union: perspectives, past, present and strategic. European Planning Studies 2001;9(2):243-54.

Bartley B. Supporting evidence-based spatial planning and analysis in Ireland: towards the development of all-island spatial databases. Paper presented at the National Institute for Regional and Spatial Analysis workshop, Maynooth, Ireland; 2007.

Brooks S, Donovan P, Rumble C. Developing nations, the digital divide and research databases. Serials Review 2005;31(4):270-8

Budic ZD. Effectiveness of geographic information systems in local planning. Journal of the American Planning Association 1994;60(2):244-63.

Carver S. The future of participatory approaches using geographic information: developing a research agenda for the 21 st century. Urban and Information Systems Association Journal 2003:15(APA I):61-71.

Communities (CEC). Directive 2000/60/EC, of 23rd October, establishing a framework for community action in the field of water policy. Official Journal of the European Union 2000;L327/1 23rd October. 
Commission of the European Communities (CEC). Directive 2001/42/EC, of 27th June, on the assessment of the effects of certain plans and programmes on the environment. Official Journal of the European Union 2001;L 197/30 21st July.

Commission of the European Communities (CEC). Directive 2002/49/EC of the European Parliament and of the Council, of 25th June, relating to the assessment and management of environmental noise. Official Journal of the European Union 2002;:L189/12 18th July.

Commission of the European Communities (CEC). Proposal, of 29th June, for a Directive of the European Parliament and of the Council establishing an infrastructure for spatial information in the community (INSPIRE); political agreement. European Parliament and the Council of the European Union; 2005.

Commission of the European Communities (CEC). Directive 2007/2/EC, of 14th March, establishing an infrastructure for spatial information in the European community (INSPIRE). Official Journal of the European Union 2007;L108/1 24th May.

Dalal-Clayton B, Sadler B. Strategic environmental assessment: a sourcebook and reference guide on international experience. London: International Institute for Environment and Development; 2004.

Dalkmann H, Herrera RJ, Bongardt D. Analytical strategic environmental assessment (ANSEA): developing a new approach to SEA. Environmental Impact Assessment Review 2004;24(4):385-402.

Department of Environment, Heritage and Local Government (DEHLG). Implementation of SEA Directive (2001/42/EC), assessment of the effects of certain plans and programmes on the environment - guidelines of regional authorities and planning authorities. Dublin: Government of Ireland; 2004a.

Department of Environment, Heritage and Local Government (DEHLG). Planning and development (strategic environmental assessment) regulations 2004. Department of Environment, Heritage and Local Government S.I. No. 436 of 2004. Dublin: Government of Ireland; 2004b.

Fischer TB. Strategic environmental assessment - an introduction; 2007. http://www. penta-eu.net/docs/WebText.pdf (last accessed: September 2010).

Fischer TB, Gazzola P. SEA effectiveness criteria - equally valid in all countries? The case of Italy. Environmental Impact Assessment Review 2006;26(4):396-409.

Fischer TB, Seaton K. Strategic environmental assessment: effective planning instrument or lost concept? Planning Practice and Research 2002;17(1):31-44.

Fischer TB. Strategic environmental assessment in transport and land use planning. London: Earthscan; 2002.

Fischer TB. Strategic environmental assessment in post-modern times. Environmental Impact Assessment Review 2003;23(2):155-70.

Geneletti D. Impact assessment of proposed ski areas: a GIS approach integrating biological, physical and landscape indicators. Environmental Impact Assessment Review 2008;28(2-3):116-30.

González A. Incorporating spatial data and GIS to improve SEA of land use plans: opportunities and limitations - case studies in the Republic of Ireland. Lambert Academic Publishing; 2010.

González A, Gilmer A, Foley R, Sweeney J, Fry J. Developing and applying a participative web-based GIS for integration of public perceptions into strategic environmental assessment. In: Mount NJ, Harvey GL, Aplin P, Priestnall G, editors. Representing, modeling and visualizing the natural environment: innovations in GIS 13. Florida: CRC Press; 2008a. p. 117-33.

González A, Gilmer A, Foley R, Sweeney J, Fry J. Technology-aided participative methods in environmental assessment: an international perspective. Computers, environment and urban systems 2008b;32:303-16.

Goodchild M.F. The spatial web: visions for a geospatial world. Unpublished paper presented at the National Centre for Geocomputation - Maynooth, Ireland. 2006.

Haklay M, Feitelson E, Doytsher Y. The potential of a GIS-based scoping system: an Israeli proposal and case study. Environmental Impact Assessment Review 1998;18 (5):439-59.

Hanzl M. Information technology as a tool for public participation in urban planning: a review of experiments and potentials. Design Studies 2007;28(3):289-307.

Harrison C, Haklay M. The potential of public participation GIS in UK environmental planning: appraisals by active publics. International Journal for Environmental Planning and Management 2002;45(6):841-64.

Horita M. Mapping policy discourse with CRANES: spatial understanding support system as a medium for community conflict resolution. Environment and planning B: planning and design 2000;27(6):801-14

Hunter GJ. Managing uncertainty in GIS. In: Longley PA, Goodchild MF, Maguire DJ, Rhind DW, editors. Geographical information systems 2: managing issues and applications. New York: John Wiley and Sons Inc.; 1999. p. 633-41.

International Association for Impact Assessment (IAIA). Strategic environmental assessment performance criteria. Special publication series. vol. 1; 2002. http:// www.iaia.org/publicdocuments/pdf/sp1.pdf. (last accessed: September 2010).

João EM. Use of geographic information systems in impact assessment. In: Porter A, Fittipaldi J, editors. Environmental methods review: retooling impact assessment for the new century. Atlanta: The Army Environmental Policy Institute; 1998. p. $154-63$.

João EM. How scale affects environmental impact assessment. Environmental impact assessment review 2002;22(4):289-310.

João EM. The importance of data and scale issues for strategic environmental assessment. Environmental impact assessment review, special issue on data and scale issues for SEA 2007;27(5):361-4.

Jordan G, Shrestha B. A participatory GIS for community forestry user groups in Nepal: putting people before the technology. International institute for environment and development, participatory learning and action notes 39; 2000.

Kangas J, Store R. Internet and teledemocracy in participatory planning of natural resources management. Landscape and urban planning 2003;62(2):89-101.
Käpylä T, Niemi I, Lehtola A. Towards an accessible web by applying PUSH technology; 1998. http://ui4all.ics.forth.gr/UI4ALL-98/kapyla.pdf (last accessed: September 2010).

Kingston R. Web-based GIS for public participation decision making in the UK. Paper presented at the empowerment, marginalisation and public participation GIS conference, Santa Barbara, California; 1998. http://www.ncgia.ucsb.edu/varenius/ ppgis/papers/kingston/kingston.html. (last accessed: September 2010).

Kingston R, Carver S, Evans A, Turton I. Web-based public participation geographical information systems: an aid to local environmental decision-making. Computers, environment and urban systems 2000;24(2):109-25.

Lillethun A. Environmental thematic user needs. Position paper presented at the infrastructure for spatial information in Europe - Environmental Thematic Coordination Group, European Environmental Agency; 2002. http://www.ec-gis. org/inspire/. (last accessed: September 2010).

Legg RJ, Taylor D. Modeling environmental influences on the locations of Irish early medieval ringforts. Geoarchaeology 2006;21(3):201-20.

Oden MD, Lentz RG. Digital divide or digital opportunity in the Mississippi delta region of the US. Telecommunications Policy 2001;25(5):291-313.

Office of the Deputy Prime Minister (ODPM). A practical guide to the strategic environmental assessment directive. London; 2005.

Onsrud HJ. Liability in the use of GIS and geographical datasets. In: Longley PA, Goodchild MF, Maguire DJ, Rhind DW, editors. Geographical information systems 2: managing issues and applications. New York: John Wiley and Sons Inc.; 1999. p. 643-52.

Palmer SCF. Habitat and management survey of areas adjacent to Orkney Mainland Moors Special Protection Area - initial report. Scottish Natural Heritage Commissioned report no. 185 (ROAME no. F02PA02); 2006.

Partidário MR. Elements of an SEA framework - improving the added-value of SEA Environmental impact assessment review 2000;20(6):647-63.

Partidário MR. Scales and associated data - what is enough for SEA needs? Environmental impact assessment review, special issue on data and scale issues for SEA 2007;27(5):460-78.

Patil AA, Annachhatre AP, Tripathi NK. Comparison of conventional and geo-spatial EIA: a shrimp farming case study. Environmental impact assessment review 2002;22(4): 361-75.

Rhind D. Geographic information - national policy issues and business models for governments. Paper presented at the Future of GI Science seminar - Maynooth, Ireland; 2008.

Runhaar H, Driessen PJ. What makes strategic environmental assessment successful environmental assessment? The role of context in the contribution of SEA to decision-making. Impact assessment and project appraisal 2007;25(1):2-14.

Rybaczuk K, MacMahon H. Accessing geographic information for Ireland. Dublin: Forbairt and the Irish Institution of Surveyors; 1995.

Siebenhüner B, Barth V. The role of computer modelling in participatory integrated assessment. Environmental impact assessment review 2004;25(4):367-89.

Simão A, Densham PJ, Haklay M. Web-based GIS for collaborative planning and public participation: an application to the strategic planning of wind farm sites. Journal of Environmental Management 2009;90(6):2027-40.

Skehan CD, González A. Spatial data management requirements and strategic environmental assessment. Paper presented at the Society of Chartered Surveyors, EuroSDR and the Dublin Institute of Technology joint workshop, Dublin, Ireland; 2006.

Skehan CD. Strategic environmental assessment, a new challenge and opportunity for development planning. Paper presented at the Strategic Environmental Assessment conference, Tullamore, Ireland; 2004.

Therivel R, Minas P. Measuring SEA effectiveness: ensuring effective sustainability appraisal. Impact assessment and project appraisal 2002;20(2):81-91.

Therivel R. Strategic environmental assessment in action. London: Earthscan, IncNet Library; 2004.

Towers G. GIS versus community: sitting power in West Virginia. Applied geography 1997; 17(2):111-25.

van Loenen B, Onsrud HJ. Geographic data for academic research: assessing access policies. Cartography and geographic information science 2004;31(1):3-17.

van Straaten D. Vulnerability maps as a tool for SEA and infrastructure planning; 1999. http://www.vista.gov.vn/VistaEnglish/VistaWeb/learn/Env.\%20Planning/texts\% 20in\%20English/P3Chap7.pdf (last accessed: September 2010).

Vanderhaegen M, Muro E. Contribution of a European spatial data infrastructure to the effectiveness of EIA. Environmental impact assessment review 2005;25(2):123-42.

Vogt P, Riitters KH, Iwanowski M, Estreguil M, Kozak J, Soille P. Mapping landscape corridors. Ecological indicators 2007:7:481-8

Weiner D, Harris TM. Community-integrated GIS for land reform in South Africa. Urban and information systems association journal 2003;15(APA II):61-73.

Wright F. Consideration of the baseline environment in examples of voluntary SEAs from Scotland environmental impact assessment review. Special issue on data and scale issues for SEA 2007;27(5):424-39.

Ainhoa González holds a PhD in Environmental Planning and works as a freelance environmental analyst in Ireland and the Basque Country - Spain. She has been involved in a diverse range of consultancy projects; her main area of expertise being the application of GIS for impact assessment of projects, plans and programmes. She is currently a research fellow in the 'Sustainable Urban Planning Decision Support Accounting for Urban Metabolism' project funded by the European Seventh Framework Programme. She also lectures GIS in several Irish universities and has contributed to a number of international workshops in SEA

Alan Gilmer is a lecturer at the Dublin Institute of Technology and teaches on environmental modelling, ecological systems, and environmental management systems. 
Ronan Foley is a lecturer at the National University of Ireland, Maynooth and teaches courses on GIS and Geographies of Health. He is also a Research Associate of National Institute for Regional and Spatial Analysis and the National Centre for Geocomputation. He has been involved in a diverse range of research and consultancy projects allied to health, social and economic analysis using GIS in both Ireland and the UK.

John Sweeney has been a lecturer at the Geography Department NUI Maynooth, since 1978 , mainly in climatology and biogeography. He has been the Irish representative on a number of European academic bodies. As one of the contributing authors and review editors of the Fourth Assessment Report of the Intergovernmental Panel on Climate Change (IPCC), he shared with several hundred other climatologists the 2007 Nobel Peace Prize.
John Fry is a senior lecturer at the Department of Environmental Resource Management and academic director for the UCD Diploma in EIA \& SEA Management since 1992. John is a member of the Training and Professional Development Committee of the International Association for Impact Assessment. He is also a member of interview and review panels for a number of Irish local authorities, and has contributed as specialist consultant to a number of Irish Environmental Impact Statements. 